\title{
Intermidialidade músico-literária em Luiz Antonio de Assis Brasil: aproximações entre $O$ inverno e depois e o Concerto para violoncelo e orquestra de Dvořák
}

Edemilson Antônio Brambilla ${ }^{\mathrm{i}}$

\section{RESUMO}

Este estudo possui como objetivo compreender a presença da intermidialidade no romance $O$ inverno e depois, de Luiz Antonio de Assis Brasil. Nesta obra, o autor parte de relações entre o universo literário e o musical para construir sua narrativa ficcional, onde o Concerto para violoncelo e orquestra do compositor checo Antonín Dvorák torna-se um ponto de referência para a estrutura do romance. Nesse sentido, ainda que essas obras tenham códigos semióticos distintos, buscamos evidenciar como os aspectos composicionais da primeira mídia (o concerto) são utilizados na construção da segunda (o romance).

Palavras-chave: Intermidialidade; Música e literatura; Luiz Antonio de Assis Brasil; Antonín Dvořák.

\section{ABSTRACT}

This study aims to understand the presence of intermediality in the novel $O$ Inverno $e$ Depois by Luiz Antonio de Assis Brasil. Inspired by the relationship between literary and musical universes, Assis Brasil builds in this work a fictional narrative in which the Concerto for Cello and Orchestra by Czech composer Antonín Dvořák plays a structural role. Although these works have different semiotic codes, I intend to discuss in this article how the compositional aspects of the first medium (concerto) are employed in the construction of the second medium (novel).

Keywords: Intermediality; Music and literature; Luiz Antonio de Assis Brasil; Antonín Dvořák.

\section{INTRODUÇÃO}

\footnotetext{
i Mestrando no Programa de Pós-graduação em Letras da Universidade de Passo Fundo (PPGL/UPF). ORCID: https://orcid.org/0000-0001-5093-2082
} 
O estudo sistemático das relações entre o universo literário e o musical vem ganhando cada vez mais espaço no ambiente acadêmico, o que se deve, em grande medida, à percepção de que esta é uma possibilidade interpretativa bastante peculiar dentro dos estudos em Literatura Comparada. Mas também, porque, cada vez mais críticos e leitores estão conseguindo mapear e compreender de forma mais detalhada o papel da música sobre a obra literária de um determinado escritor, fazendo com que, por conta disso, tenha-se novas perspectivas interpretativas desses textos.

No caso específico das relações músico-literárias, não são raras, especialmente em meio ao cenário literário brasileiro, referências à música presentes em obras de escritores renomados. Isso ocorre, por exemplo, nas obras de Machado de Assis e Mário de Andrade; ou então, em boa parte dos textos ficcionais de escritores sul-riograndenses como Erico Verissimo, Luís Fernando Verissimo, Charles Kiefer, e Luiz Antonio de Assis Brasil.

No presente artigo, de um modo mais específico, estudamos a presença intermidiática da música no romance $O$ inverno e depois (2016), de Luiz Antonio de Assis Brasil. Nessa obra, Assis Brasil parte de relações entre esses dois universos, o literário e o musical, para construir uma narrativa na qual o Concerto para violoncelo e orquestra do compositor checo Antonín Dvořák torna-se uma referência para a estrutura romanesca. Nesse sentido, buscamos discutir como os aspectos musicais que compõem essa primeira mídia (o concerto) são utilizados para a construção da segunda (o romance), mesmo que elas pertençam a códigos semióticos distintos.

Tomando a concepção de intermidialidade como o conceito central deste estudo, a fim de traçar os paralelos entre as duas obras analisadas - a de Assis Brasil e a de Dvořák -, as seções subsequentes versam sobre o conceito de intermidialidade e sua implicação no estudo das relações músico-literárias para que em seguida possamos compreender como esse percurso teórico nos possibilita aproximar as obras de Assis Brasil e de Dvořák.

\section{A INTERMIDIALIDADE E O ESTUDO DAS RELAÇÕES MÚSICO- LITERÁRIAS}


O conceito de intermidialidade vem ganhando cada vez mais espaço em estudos voltados às relações entre campos distintos do saber e sua aplicabilidade perpassa o universo das artes, das ciências humanas, da antropologia, da sociologia, da semiótica, e dos estudos de comunicação. A abrangência do termo demonstra também, em um primeiro momento, a dificuldade em delimitar e/ou definir de um modo mais específico seu objeto de estudo. De maneira geral, de acordo com Clüver (2011, p. 9), a intermidialidade "implica todos os tipos de interrelação e interação entre mídias; uma metáfora frequentemente aplicada a esses processos fala de 'cruzar as fronteiras' que separam as mídias”. É claro que, por conta de sua vasta possibilidade interpretativa, variando de acordo com a maneira com a qual cada área do saber se apropria do termo, essa noção acaba sendo de difícil delimitação. A primeira barreira para isso é que o conceito de intermidialidade está, necessariamente, atrelado ao conceito de mídia, e sua delimitação também é pautada por controvérsias no meio acadêmico, recebendo interpretações distintas que irão depender da perspectiva assumida, do campo de estudo e dos objetivos de cada pesquisa. Em uma das definições mais amplamente aceitas acerca da noção de mídia, Wolf (2011, p. 2; tradução nossa) afirma:

\footnotetext{
Mídia, como utilizada em estudos literários e de intermidialidade, são meios de comunicação convencionalmente e culturalmente distintos, especificados não apenas por canais institucionais ou técnicos particulares (ou por apenas um canal) mas, prioritariamente, pelo uso de um ou mais sistemas semióticos na transmissão pública de conteúdos que incluem, mas não se restringem, a “mensagens" referenciais. De maneira geral, a mídia faz diferença no tipo de conteúdo que pode ser evocado, em como esses conteúdos são apresentados e em como são experimentados.
}

No que diz respeito à noção de intermidialidade, por sua vez, temos também essa dificuldade de definição. De acordo com Rajewsky (2012, p. 18), a intermidialidade é

[...] um termo genérico para todos aqueles fenômenos que (como indica o prefixo inter) de alguma maneira acontecem entre as mídias. "Intermidiático", portanto, designa aquelas configurações que têm a ver com um cruzamento de fronteiras entre as mídias e que, por isso, podem ser diferenciadas dos fenômenos intramidiáticos assim como dos fenômenos transmidiáticos, por exemplo, o aparecimento de um certo motivo, estética ou discurso em uma variedade de mídias diferentes.

A intermidialidade, ainda de acordo com a autora, além de designar o fenômeno supracitado, serve como uma importante ferramenta de pesquisa que não apenas se 
relaciona com as mídias individuais, mas também com as configurações híbridas, onde elementos verbais, visuais, auditivos, cinéticos e performativos agem de maneira conjunta, criando, assim, formas mistas. Ainda sobre o conceito de intermidialidade, Wolf, em seu texto intitulado (Inter)mediality and the Study of Literature, afirma:

\begin{abstract}
Assim como no caso de uma mídia, a (inter)midialidade também pode ser concebida de modo mais restrito ou mais amplo: o sentido restrito foca na presença de mais de uma mídia dentro de um artefato humano. Ao contrário dessa definição "intracomposicional", eu proponho uma definição mais ampla que segue o pensamento de Irina O. Rajewsky: intermidialidade, nesse sentido amplo, se aplica a qualquer transgressão de fronteiras entre mídias convencionalmente distintas... e compreende, assim, tanto relações "intra" como "extra-composicionais" entre diferentes mídias (WOLF, 2011, p. 3; tradução nossa).
\end{abstract}

A fim de elucidar melhor tal interpretação feita acerca do conceito de intermidialidade, pode-se citar o estudo feito por Rajewsky (2015) que sugere três subcategorias analíticas para o uso de tal conceito - apresentadas aqui de acordo com a interpretação feita por Ghirardi, Rajewski e Diniz (2020, p. 18-19). Vejamos: a) Intermidialidade no sentido mais restrito de transposição midiática, isto é, a transformação de um texto fonte ancorado em uma mídia específica que através de uma transformação midiática gera uma outra mídia; b) Intermidialidade no sentido mais restrito de combinação de mídias, também denominada multi ou plurimidialidade, o que implica a combinação e portanto a copresença de pelo menos duas mídias ou formas midiáticas de articulação percebidas como distintas (por exemplo, manuscritos com iluminuras, HQs, graphic novels, arte sonora e, de uma perspectiva histórica, também o teatro, a ópera e o cinema); e c) Intermidialidade no sentido mais restrito de referências intermidiáticas, que significa a superação de fronteiras midiáticas não por envolver de fato, isto é, materialmente, mais de uma mídia ou forma midiática de articulação como na combinação midiática (copresença), mas por referir-se a uma outra mídia, por exemplo, tematizando, evocando ou imitando/simulando certos elementos, técnicas ou estruturas de outra mídia, utilizando seus próprios meios e instrumentos específicos para fazê-lo. Isso inclui, por exemplo, referências na pintura à fotografia (como em pinturas fotorrealistas que criam a ilusão de qualidade fotográfica valendo-se dos meios e instrumentos da pintura); da mesma forma, referências em filmes à pintura, em textos 
literários a filmes (a chamada escrita fílmica), à música (romances musicais) ou a obras das Belas Artes (transposition d'art, écfrase) etc.

No presente estudo, voltamo-nos principalmente a esta terceira ocorrência intermidiática, uma vez que, ao estudarmos as relações entre o universo literário e o musical, de modo especial, como o Concerto para violoncelo e orquestra de Dvořák se evidencia na narrativa do romance $O$ inverno e depois, de Assis Brasil. Em certa medida, estamos buscando compreender quais as técnicas ou estruturas da primeira mídia são utilizadas na construção da segunda.

Essas relações, antes de tudo, precisam ser compreendidas em seu caráter de dialogicidade e cooperação mútua (quando for o caso), para que então passem a constituir um exemplo concreto de intermidialidade. No caso específico das relações músico-literárias, Wolf (1999) define duas maneiras principais em que essa relação intermidiática ocorre, quais sejam: a direta/manifesta e a indireta/velada. A primeira delas, denominada intermidialidade direta/manifesta diz respeito às relações em que ambas as artes envolvidas aparecem com o seu significante característico e permanecem distintas entre si, tal como ocorre na ópera, onde, normalmente, podemos distinguir o que é literatura/teatro daquilo que é música, ainda que ambas estejam envolvidas no mesmo objeto artístico. Já o segundo caso, a intermidialidade indireta/velada, refere-se às relações em que uma das artes envolvidas é a dominante do processo intermidiático, de modo que a outra torna-se encoberta pela principal, como ocorre, por exemplo, no caso das "ficções musicalizadas", onde, por mais que possam imitar o universo musical, continuam sendo literatura.

Sobre a ficção musicalizada enquanto um exemplo da relação indireta/velada músico-literária, Wolf (1999, p. 48; tradução nossa) afirma:

\footnotetext{
É necessário enfatizar que podemos falar de tentativas de "musicalização" da literatura apenas se algum tipo de "iconicidade" intermidiática - texto que imita música - ocorre numa obra literária. A musicalização da ficção é um caso especial de intermidialidade velada músico-literária que envolve o modo da imitação. Mais precisamente, ela consiste na formatação do "discurso" de um romance ou conto (afetando, por exemplo, o material linguístico, a disposição ou a estrutura da narrativa, e as imagens utilizadas) e, em alguns casos, também da história (o conteúdo da narrativa), de tal modo que similaridades ou analogias "icônicas” verificáveis [...] com (uma peça de) música ou com partes dele. Como resultado, o leitor tem a impressão de que a música está envolvida na significação da narrativa [...] e que a presença da música pode ser indiretamente experimentada durante a leitura.
} 
É com base nessa concepção de intermidialidade indireta/velada músicoliterária, constituída por meio de uma ficção musicalizada, que estruturamos nossa leitura do romance $O$ inverno e depois, de Luiz Antonio de Assis Brasil, e sua consequente semelhança com o Concerto para violoncelo e orquestra de Dvořák.

Por fim, com o intuito de melhor elucidar as possíveis aproximações que traçamos entre o Concerto para violoncelo e orquestra e o romance $O$ inverno e depois, é importante salientarmos a perspectiva analítica da qual nos ocupamos para fazer tais afirmações. Estamos alinhados com a interpretação feita por Seaton (2020), onde, ao analisar a sonata A tempestade (1802), de Beethoven, o pesquisador sugere que os meios e técnicas disponíveis na música dos séculos XVIII e XIX seriam capazes de representar o enredo e a voz narrativa em obras musicais. Ainda que a obra musical esteja dissociada do gênero literário, em alguns casos, ela consegue evocar pelo menos dois aspectos imprescindíveis à construção narrativa, a saber: enredo e voz.

É assim que compreendemos o Concerto para violoncelo e orquestra de Antonín Dvořák. Ainda que não possua em sua composição as características narrativas da ficção literária, o concerto apresenta um discurso musical capaz de nos sugerir um enredo que é narrado ao longo de seus três movimentos; e também uma voz narrativa, à medida em que determinados personagens musicais e suas questões emocionais, muito possivelmente derivadas das motivações de seu compositor, emergem.

\section{DIÁLOGOS ENTRE O INVERNO E DEPOIS E O CONCERTO PARA VIOLONCELO E ORQUESTRA}

Publicado no ano de 2016 pela editora L\&PM, O inverno e depois reflete, para além de referências autobiográficas do escritor, a relação mútua de música e literatura no campo ficcional da obra. O livro narra a história de Julius, um violoncelista da Orquestra Sinfônica Municipal de São Paulo. O personagem decide passar um período em isolamento na Estância Júpiter, localizada em sua cidade natal, no interior do pampa gaúcho, com o intuito de executar o difícil Concerto para violoncelo e orquestra de Antonin Dvořák. No entanto, conforme Cury e Souza (2018), a busca pela musicalidade da peça de complexa execução excede o campo técnico da música e torna-se alvo de outros dois grandes conflitos ainda não resolvidos: o não enfrentamento à meia-irmã 
Antônia (sua grande paixão da juventude) e a brusca interrupção do relacionamento amoroso deles.

Tal como ocorre no romance de Assis Brasil, o concerto de Dvořák pode ser compreendido, nas palavras de Mota (2015), como um concerto de regresso à casa, já que, nessa composição, as influências composicionais americanas teriam sido reduzidas, dando lugar ao estilo nacionalista checo, um possível reflexo da falta que o compositor sentia de sua terra natal e de seu círculo social. Na sua vertente emocional, o concerto de Dvořák teria sido inspirado na saudade do lar e nas memórias do seu país e do seu povo. Ainda nesse sentido, Cury e Souza (2018) afirmam que, além de toda a nostalgia da terra natal e de ser marcada pela memória, a peça de Dvořák ainda tem outra motivação: o amor não resolvido de Dvořák por sua cunhada Josefina, cuja morte foi iminente no período da composição do concerto, o que supostamente levou o compositor a sinalizar, especialmente no segundo movimento da peça, uma homenagem à mulher amada.

Além disso, as relações entre o romance de Assis Brasil e o Concerto de Dvořák podem ser observadas também em sua estrutura narrativa. São três os espaços-tempos em que a história de Julius se passa, a saber: a infância do personagem - uma parte no Rio Grande do Sul, outra em São Paulo; a juventude, em Würzburg, na Alemanha; e $a$ vida adulta, no tempo presente, focalizando seu retorno à casa da infância. Segundo Cury e Souza (2018), assim como há três espaços-tempos no romance, o concerto é dividido em três movimentos (Allegro, Adagio ma non troppo e Finale). Cada parte da narrativa de Assis Brasil se assemelha a um dos movimentos do concerto, tanto em questões técnicas (andamento, tonalidade, sequência narrativa), quanto na proposta musical da obra (efeitos pretendidos a partir de determinadas construções musicais).

Para Cury e Souza (2018, p. 7), o Concerto para violoncelo e orquestra, divido em três movimentos (Allegro, Adagio ma non troppo e Finale), possui partes melódicas diferentes em seus formatos, nas suas intenções, no modo como os instrumentos dialogam entre si. Embora tenha sido escrito em dez capítulos, podemos também extrair do romance $O$ inverno e depois três partes principais que se articulam no espaço e tempo narrativos. Cada espaço-tempo do romance se assemelha a um movimento do concerto, como já colocado anteriormente. Mas não somente isso, uma vez que a arquitetura da narrativa se desenvolve, no decorrer dos dez capítulos, com a apropriação 
verbal das três estruturas características de cada movimento da peça musical. A estrutura da forma-sonata, oriunda do primeiro movimento do concerto, reverbera nas passagens da narrativa que encenam a infância do personagem Julius. A estrutura de forma ternária, proveniente do segundo movimento, manifesta-se nas partes relacionadas ao que Julius viveu na Alemanha. E, finalmente, a estrutura da forma rondó, originária do terceiro movimento, corresponde ao tempo presente da narrativa.

O primeiro movimento do Concerto para violoncelo e orquestra, denominado Allegro, estrutura-se na forma de uma sonata clássica - também conhecida como forma de primeiro movimento (sonata-allegro), ou então, simplesmente como forma-sonata. De acordo com Cury e Souza (2018, p. 7), tal forma consiste na utilização, no decorrer do movimento, de dois materiais melódicos distintos denominados temas: uma espécie de "refrão" que é moldado e modificado de acordo com a necessidade e a vontade do compositor, sendo que cada tema normalmente apresenta uma tonalidade diferente. Tonalidade refere-se, basicamente, a um sistema de relações hierárquicas entre notas musicais com características melódicas e harmônicas próprias.

Então, na estrutura musical da forma-sonata tem-se, necessariamente, dois temas com tonalidades e características distintas um do outro, que passam a ser trabalhados numa sequência narrativa estruturada da seguinte maneira: exposição, parte em que ambos os temas contrastantes são apresentados; desenvolvimento, parte em que os temas passam por uma remodelação e reestruturação, havendo novamente um conflito entre os dois; e reexposição, parte em que ocorre a recapitulação do material melódico utilizado na exposição, havendo, dessa maneira, a resolução da tensão criada entre os dois temas iniciais. Por fim, tem-se uma seção de encerramento do movimento, denominada coda.

A maneira como Assis Brasil estrutura e descreve a infância da personagem Julius em $O$ inverno $e$ depois se assemelha com a forma como Dvořák trabalha os elementos musicais do Concerto para violoncelo e orquestra, uma vez que, a exposição do primeiro movimento da obra de Dvořák possui dois temas contrastantes entre si, que são expostos tanto pela orquestra quanto pelo violoncelo solo: "um tema viril e rítmico e um outro melódico, de certa forma feminino" (MOTA, 2015, p. 101). O do desenvolvimento, por sua vez, apresenta materiais extraídos do primeiro tema, que acabam sofrendo todo tipo de transformação e, até mesmo, evoluindo para conjuntos inteiros de variações melódicas (SUPKA, c2020). A reexposição do concerto retoma o 
material melódico do segundo tema, num momento que, de acordo com Bian (2017, p. 23), "parece expressar um estado de ser confiante, majestoso e alegre". Para finalizar o primeiro movimento do concerto de Dvořák, temos uma coda construída principalmente com o material melódico do primeiro tema que nos remete a uma sensação festiva e alegre.

Em $O$ inverno e depois, portanto, podemos perceber reflexos dessa estrutura musical. A infância da personagem assisiana, Julius, é marcada pelos intensos conflitos deste com sua meia-irmã Antônia (filha de seu pai com uma amante). Dessa maneira, Antônia assume um papel primordial nos conflitos, dramas e cenas da infância de Julius que são apresentados ao longo de toda a narrativa de Assis Brasil. Assim, podemos considerar que cada tema do Concerto esteja representado no romance por cada um dos dois personagens principais: Julius, o primeiro tema (Tema A), e Antônia, o segundo tema (Tema B).

A seção narrativa entendida como exposição, portanto, apresenta o primeiro tema, isto é, Julius, onde é feita uma longa descrição dessa personagem, começando pelo seu nascimento, até o período que antecede sua viagem de estudos à cidade alemã de Würzburg. De acordo com Bian (2017, p. 23), a exposição do primeiro tema do concerto sugere uma "canção de lirismo extático e profundamente triste". Para Cury e Souza (2018, p. 8), profundamente triste e num lirismo em êxtase se constituem, também, as primeiras descrições da história de Julius: o menino precoce, mas de um jeito errante, que teve que lidar com a saída traumática do Rio Grande do Sul, da qual ele se recorda com dor e angústia, com a perda do pequeno violino branco e com a morte dos pais num acidente de carro, levando-o a depositar no violoncelo, e, portanto, na música, todos os matizes de sua alma órfã.

O segundo tema do Concerto de Dvořák, conforme Pombo (2007), é exposto primeiramente pela trompa em pianissimo, como um sussurro misterioso. Esta é também a forma como Antônia, personagem que representa nosso segundo tema da exposição é apresentada na narrativa assisiana, de maneira "pianíssima", breve, sutil e envolta em intensos mistérios. Descrita sob a ótica de Julius, a conflituosa e triste relação entre os dois irmãos é denunciada pelo narrador em afirmações como: "Ele (Julius) não tem espaço interior para nele acrescentar uma meia-irmã" (ASSIS BRASIL, 2016, p. 33). 
Após a exposição inicial dos dois temas conflitantes - Julius (tema A) e Antônia (tema B) -, tem-se o desenvolvimento da narrativa, o qual, assim como no concerto de Dvořák, é construído com base no material do primeiro tema narrativo, ou seja, Julius. Então, podemos considerar como partes referentes a esse desenvolvimento, as cenas como a reminiscência de Julius com relação a partida da família do Rio Grande do Sul para São Paulo e as passagens onde Julius se recorda dos pais e, já adulto, rememora cenas da infância e momentos íntimos de sua família. Vejamos como o narrador nos apresenta esses fatos:

Julius se aproxima da penteadeira. Seus passos fazem ranger as tábuas do assoalho. [...] No grande espelho basculante e oval ele vê refletido aquele homem maduro, de óculos, que quer disfarçar sua estranheza ao se enxergar de poncho. Ao lado do espelho, uma pequena foto. É ele, criança. [...] Nesta mesma foto, atrás de si, de pé, está o pai Latinista, com um lenço branco no pescoço e botas de fole [...]. Já pensa na mãe. Sempre que a traz à lembrança, nunca é de maneira completa (ASSIS BRASIL, 2016, p. 112-113).

Poderíamos aqui citar diversas passagens que também se encaixam no que denominamos como sendo pertencentes à seção de desenvolvimento; todas elas são desencadeadas pela memória que Julius tem de seu passado, pela carga emocional e pelas importantes decisões tomadas pelo herói assisiano. Após o desenvolvimento temos, portanto, a seção denominada reexposição. Esta, como já se disse, caracterizada pelos materiais derivados do segundo tema. Tal como ocorre no segundo movimento do concerto, temos novamente a presença de Antônia na narrativa, ainda que isso só ocorra em um momento já bastante avançado do romance de Luiz Antonio de Assis Brasil. De acordo com Cury e Souza (2018, p. 9), nessa reexposição, Julius traz à memória os diversos conflitos relacionados com a existência de Antônia e, finalmente, consegue estabelecer um diálogo com a irmã. Tudo isso abre o caminho para a coda, um encerramento festivo, tal como no concerto, dessa parte da vida de Julius. Ela ocorre quando Julius pede perdão à irmã e sente que só então essa parte do passado não mais o assombrará. Vejamos um trecho que parece representar essas questões:

- Antônia, [...] Não vou conseguir explicar. O importante é que você saiba disso. [...] Vencendo um tabu, ele se vê dizendo: - Preciso te pedir que me perdoe. [...] Por todos esses anos de perseverança. Você nunca desistiu. Você veio à minha procura. Você achou um motivo. [...] - Nunca perdi a esperança de que um dia, muito no futuro - ela gagueja -, nós nos encontraríamos. - 
Este é o dia, Antônia, - Ele põe o braço sobre os ombros dela, e a traz junto a si (ASSIS BRASIL, 2016, p. 323-324).

Percebe-se, portanto, que parte da narrativa construída por Assis Brasil em $O$ inverno e depois parece refletir a estruturação da forma-sonata oriunda do primeiro movimento do Concerto para violoncelo e orquestra, de Antonín Dvořák, uma vez que, de acordo com Cury e Souza (2018, p. 9), "tanto os temas contrastantes, como o conflito entre áreas tonais podem ser caracterizados como a questão central do movimento". A respeito desse conflito, Oliveira (2002, p. 132-133) afirma:

[...] apresentado na exposição e posteriormente desenvolvido, mas por uma instabilidade inicial, sob a forma de duas áreas tonais conflitantes. Essa tensão acentua-se durante o desenvolvimento, que não apenas entrelaça os temas, mas, sobretudo, aventura-se por áreas harmônicas mais distanciadas. A recapitulação [reexposição] resolve essas tensões eliminando o conflito de tonalidades. [...]. Tem-se, assim, uma estrutura ABA', representando instabilidade/intensificação da instabilidade/resolução.

$\mathrm{Na}$ interpretação de Cury e Souza (2018, p. 10), a instabilidade, metaforicamente associada às passagens iniciais em que o personagem Julius tem uma relação não resolvida com a irmã Antônia. A intensificação da instabilidade, associada aos trechos em que Julius volta à casa da infância e os sentimentos negativos em relação à irmã são nutridos pelas memórias do passado. A resolução, associada às partes em que Julius consegue estabelecer um diálogo com Antônia, a possibilidade da reconciliação entre ambos e a expectativa de uma nova amizade.

Como se percebe nesse primeiro trecho analisado, as referências que aproximam o texto de Luiz Antonio de Assis Brasil ao concerto de Antonín Dvořák parecem se ancorar nos aspectos emotivos e sentimentais presentes nas duas obras. Isto é, conforme uma leitura mais subjetiva. Sobre a influência da forma-sonata no texto literário e a complexidade em delinear de um modo claramente bem definido suas relações, o próprio Assis Brasil (2015, p. 12) afirma:

O texto literário é, de todas as artes, o mais suscetível de ser influenciado por outras formas de expressão, e hoje é possível afirmar que os movimentos da forma-sonata têm muito a ver com os capítulos ou segmentos da narrativa literária. É claro que não se fala de uma influência direta, rígida, e constatável à primeira leitura: trata-se mais de uma espécie de atitude narrativa que segmenta o texto em fragmentos que, muitas vezes, alternam as expressões do introspectivo com o extrospectivo, o cômico com o sério, a ação com a reflexão. 
Após esse primeiro movimento do Concerto para violoncelo e orquestra, construído com base na forma-sonata, temos o segundo movimento, intitulado Adagio ma non tropo, construído com base em uma forma ternária, ou seja, dividida em três seções (ABA'), sendo que as seções A e A' são similares, enquanto a seção B apresenta um novo material melódico, sendo contrastante com as demais. A seção A traz elementos do primeiro tema (Tema A) presente no primeiro movimento do concerto, no entanto, aqui apresentado de maneira modificada, se revestindo, conforme Bian (2017, p. 24), de "um caráter pacífico e silencioso semelhante a uma canção de ninar". Na seção B, por sua vez, Dvořák introduz uma nova melodia pacífica e melancólica. Na seção A', por fim, tem-se o encerramento do movimento e, de acordo com Mota (2015, p. 153), esta apresenta um “carácter de resignação, de aceitação pacífica de todos os acontecimentos".

Na narrativa de Assis Brasil, os trechos referentes a esta passagem do concerto se concentram no período em que Julius passou em Würzburg, na Alemanha, bem como na história de amor vivida entre a personagem assisiana e a flautista uruguaia Constanza Zabala. Assim como o segundo movimento do Concerto para violoncelo e orquestra divide-se em três seções, são também três os capítulos da narrativa de Assis Brasil que se passam inteiramente em Würzburg, a saber: os capítulos 2, 4 e 6. Conforme supracitado, os capítulos 2 e 6 (correspondentes às seções A e A'), possuem as mesmas características, uma vez que narram a estadia de Julius em Würzburg, quando este conhece Constanza Zabala, perpassando também as cenas do romance vivido pelos dois, culminando no dramático fim do relacionamento entre ambos.

$\mathrm{O}$ capítulo 4, então, correspondente à seção $\mathrm{B}$ do concerto, apresenta um contraste temático na representação da estadia de Julius na cidade alemã. De acordo com Cury e Souza (2018, p. 10-11), esta representação contempla a narrativa da história de Julius antes de se envolver com Constanza (desde sua chegada à Alemanha), o processo de adaptação na cidade, o estabelecimento de relações sociais, a morte chocante do seu professor de violoncelo e, sobretudo, a ousada decisão, que permeia toda a história, de executar o Concerto para violoncelo e orquestra, de Dvořák. Além disso, a semelhança entre a parte da narrativa de Julius na Alemanha e esse movimento do concerto também se dá pelas intenções emocionais sugeridas e pelas temáticas 
propostas em ambas as obras, como já se disse: a nostalgia da terra natal, a expressão de lamento e dor do protagonista (Julius/violoncelo solo) e as fortes sensações de amor, paixão e solidão.

A título de exemplificação do que fora exposto sobre as semelhanças entre a seção B do segundo movimento do concerto de Dvořák e o romance de Assis Brasil, podemos citar uma passagem da narrativa onde Julius se encontra desacreditado após a morte de seu professor e a despedida de uma amiga. No trecho, o narrador do romance assisiano afirma: "O que Julius sentia era pesar, revolta e abandono. Em poucos dias ele perdera duas pessoas que lhe davam a certeza de que era ainda possível acreditar na Arte e, por extensão, no ser humano" (ASSIS BRASIL, 2016, p. 162).

O terceiro e último movimento do Concerto para violoncelo e orquestra, por sua vez, denomina-se Finale, Allegro moderato. Nele, tem-se um discurso musical construído na forma rondó, onde "o tema principal (A) continua sempre retornando, existindo, porém, seções contrastantes (B, C, etc.) entre cada retorno ao (A) anterior" (BENNETT, 2007, p. 51). Sobre a construção musical feita por Dvořák, Supka afirma que a abordagem desse terceiro movimento "se dá num contexto de 'mover-se da escuridão para a luz', o que reflete a alegria de Dvořák por seu retorno definitivo à sua terra natal: o último movimento do concerto foi escrito poucas semanas antes de sua partida de Nova York" (c2020).

Esta suposta abordagem do compositor checo é refletida em alguns fatos contidos na narrativa de Assis Brasil, já que, Julius decide fazer uma viagem de volta à casa onde passou os primeiros anos de sua vida, na Estância Júpiter, com o intuito de encontrar ali um local sossegado para que possa estudar o concerto de Dvořák, distante da turbulência e agitação da cidade de São Paulo, e onde também possa resolver os conflitos e dramas que o acompanham desde a infância, configurando-se, assim, em uma espécie de acerto de contas com seu passado.

Há algumas semelhanças entre as observações de Supka sobre Dvořák e as ações de Julius. Muito apropriadamente, Cury e Souza (2018, p. 11) destacam:

Podemos considerar, então, que o personagem entra numa espécie de "escuridão", sendo um homem saudoso e que, melancolicamente, se considera incompleto. O regresso à casa da infância para estudar o Concerto, marcado já nas primeiras páginas do romance, bem como toda sua trajetória até finalmente conseguir dominar o violoncelo e executar a peça - como exposto no último capítulo - também representam, por assim dizer, uma 
passagem da "escuridão para a luz", uma vida que ganha, de fato, um significado, uma história.

No que diz respeito às seções desse movimento do concerto, a forma rondó apresenta a seguinte sequência temática: $\mathrm{ABA}^{\prime} \mathrm{CA}$ ”, sendo que as seções $\mathrm{A}, \mathrm{A}^{\prime}$ e A" derivam do mesmo material melódico, enquanto as seções B e C são seções contrastantes, construídas com material melódico diferente das demais. Desse modo, as seções A, A' e A", quando transpostas para a narrativa de Luiz Antonio de Assis Brasil, correspondem às partes em que Julius viaja e se hospeda na Estância Júpiter, enquanto as seções contrastantes B e C, respectivamente, fazem referência às partes intercaladas na narrativa que, embora situadas no tempo presente da personagem, formam um elo temporal com os demais aspectos da história narrada por Assis Brasil.

De acordo com Cury e Souza (2018, p. 11-12), a seção A se localiza no primeiro capítulo (intercalada por lembranças da infância), em que é narrada a desventura de Julius ao ter sua mala extraviada, e a viagem de carro de Porto Alegre até a Estância Júpiter. A seção B se localiza no terceiro capítulo, quando Julius se depara com a casa da infância e se sente estrangeiro no seu próprio lar, na sua própria memória. Após essa parte, encontra-se a seção A', no quinto capítulo, no qual a narrativa se volta mais para uma descrição da casa de Julius - mas também as impressões psicológicas do protagonista. A seção C, por sua vez, encontra-se no sétimo capítulo da obra de Assis Brasil, uma parte também repleta de lembranças do passado de Julius.

A última seção do concerto, A”, conforme Cury e Souza (2018, p. 13), é onde Dvořák utiliza materiais do primeiro e segundo movimentos anexado a uma longa coda, que caminha para um final festivo. Mesmo no clima de festividade, acontece novamente uma referência à canção Lasst mich allein (Deixe-me só) - que também aparece no segundo movimento do concerto. Esta referência seria uma confirmação do interesse do compositor em prestar uma homenagem melancólica a sua amada Josefina, a qual já teria falecido no momento da composição. Na narrativa, por contraste, essa seção ocorre nos últimos capítulos, em que são rememoradas passagens da infância de Julius e da sua estadia em Würzburg, bem como ocorre o reencontro com Constanza Zabala. Tal como o concerto, o romance de Assis Brasil termina num clima festivo, após Julius conseguir executar o concerto. No entanto, esse sentimento é atravessado por uma reflexão introspectiva e melancólica que diz: "no entanto, para sempre saudoso, solitário e 
incompleto, tal como os personagens dos romances" (ASSIS BRASIL, 2016, p. 344). Segue-se então uma súbita suspensão da narrativa que dá ao leitor a sensação de ter sido excluído de um mundo que só existirá para os personagens.

Percebe-se que as partes da narrativa de Assis Brasil que refletem o último movimento do concerto de Dvořák dizem respeito, principalmente, às lembranças de Julius dos motivos que o levaram ao isolamento na Estância Júpiter e ao estudo do Concerto para violoncelo e orquestra, que funcionam como uma espécie de autorreflexão da personagem, localizadas, como vimos, no tempo presente, mas com grande significância para a compreensão dos fatos ocorridos no passado de Julius.

\section{CONSIDERAÇÕES FINAIS}

É importante compreendermos que, ainda que tenhamos apontado principalmente as semelhanças entre as duas obras, também poderíamos expandir este estudo buscando assinalar, de modo mais concreto, quais aspectos das criações de Assis Brasil e de Dvořák podem ser vistos como diferentes ou conflitantes. Se é que podemos apontar uma dessas diferenças, no caso do concerto, a suposta relação amorosa de Dvořák jamais poderia se concretizar novamente, uma vez que sua amada Josefina teria falecido. Já no caso da ficção assisiana, apesar de alguns conflitos pessoais ainda parecerem não solucionados, denunciando a complexidade psicológica de Julius, a sua realização amorosa se concretiza, juntamente com a execução do concerto de Dvořák, seu objeto de estudo ao longo de todo o romance.

Não foi o intuito deste artigo, conforme supracitado, analisar de modo pormenorizado e fastidioso as relações entre a obra de Assis Brasil e o concerto de Dvořák. O que buscamos, antes de tudo, foi lançar luz em uma relação músico-literária que encontra nos teóricos da intermidialidade uma possível forma de interpretação. Evidenciam-se, diante do exposto neste texto, as relações que aproximam as duas obras em questão, uma vez que Assis Brasil parece transpor a fronteira entre as duas mídias (literatura e música), para criar um texto que evoca uma relação mútua no plano estruturante e narrativo de sua ficção.

\section{Referências}


ASSIS BRASIL, L. A. A criação literária e música. Letras em Revista, Teresina, v. 06, n. 01, jan./jun. 2015. p. 8-15.

ASSIS BRASIL, L. A. O inverno e depois. Porto Alegre: L\&PM, 2016.

BENNETT, R. Forma e estrutura na música. Tradução: Luiz Carlos Csëko. Rio de Janeiro: ZAHAR, 2007.

BIAN, Z. A Pedagogical Analysis of Dvorak's Cello Concerto in B Minor, Op. 104. 2017. 69 p. Tese (Doutorado em Artes Musicais) - The Faculty of Graduate and Postdoctoral Studies, The University of British Columbia, Vancouver, 2017.

CLÜVER, C. Intermidialidade. Pós: Belo Horizonte, v. 1, n. 2, p. 8 - 23, nov. 2011. Disponível em: https://periodicos.ufmg.br/index.php/revistapos/article/view/15413/12270. Acesso em: 31 maio 2021.

CURY, M. Z. F.; SOUZA, G. A. L. Entre modulações musicais e literárias: O inverno e depois, de Luiz Antonio de Assis Brasil. Navegações, Porto Alegre, v. 11, n. 1, p. 3-14, jan./jun. 2018.

GHIRARDI, A. L. R.; RAJEWSKY, I.; DINIZ, T. F. N. Intermidialidade e referências intermidiáticas: uma introdução. Revista Letras Raras, v. 9, n. 3, p. 11-23, ago. 2020. Disponível em: http://dx.doi.org/10.35572/rlr.v9i3.1902. Acesso em: 31 mai. 2021.

MOTA, R. P. R. B. Concerto para violoncelo e orquestra em Si menor, Op. 104, de Antonín Dvořák: a obra enquanto objeto para a elaboração de um documento pedagógico. 2015. 223 p. Dissertação (Mestrado em Música) - Curso de Pós-Graduação em Ensino de Música, Faculdade de Ciências Humanas e Sociais da Universidade Lusíada de Lisboa, Lisboa. 2015.

OLIVEIRA, S. R. Literatura e Música: modulações pós-coloniais. São Paulo: Perspectiva, 2002.

POMBO, F. Concerto para violoncelo e orquestra em Si menor, op. 104. Casa da música, 2007. Disponível em: <https://www.casadamusica.com/artistas-eobras/obras/c/concerto-para-violoncelo-e-orquestra-em-si-menor-op104-antonindvo\%C5\%99ak/\#tab=0>. Acesso em: 31 mai. 2021.

RAJEWSKY, I. Intermidialidade, Intertextualidade e "Remediação": uma perspectiva literária sobre a intermidialidade. Tradução: Thaïs Flores Nogueira Diniz e Eliana Lourenço de Lima Reis. In: DINIZ, T.F.N. Intermidialidade e Estudos Interartes: desafios da arte contemporânea. Belo Horizonte, UFMG: 2012, p. 15-46.

RAJEWSKY, I. Le terme d'intermédialité en ébullition: 25 ans de débat. In: FISCHER, C. (org.) Intermédialités. Paris, Mondial Livres, 2015, p. 19-54. 
SEATON, D. Narrativa na música: o caso da sonata "A tempestade", de Beethoven. In: FIGUEIREDO, C. A. P.; OLIVEIRA, S. R.; DINIZ, T. F. N. A intermidialidade e os estudos interartes na arte contemporânea. Santa Maria: Ed. UFSM, 2020. p. 241-264.

SUPKA, O. Concerto for cello and orchestra. Antonin Dvořák, c2020. Informações sobre obras. Disponível em: <http://www.antonin-dvorak.cz/en/concerto-for-cello2>. Acesso em: 31 maio 2021.

WOLF, W. (Inter)mediality and the Study of Literature. CLCWeb: Comparative Literature and Culture 13.3 (2011). Disponível em: https://doi.org/10.7771/14814374.1789. Acesso em: 31 mai. 2021.

WOLF, W. Musicalized fiction and intermediality: theoretical aspects of word and music studies. In: BERNHART, Walter; SCHER, Steven Paul; WOLF, Werner (Org.). Word and music studies: Defining the Field. Atlanta: Rodopi, 1999. p. 37-58

Recebido em: 31/05/2021 Aceito em: 23/08/2021 